\title{
Studying the biodistribution of positron emission tomography reporter probes in mice
}

\author{
Shahriar S Yaghoubi, Frank Berger \& Sanjiv S Gambhir \\ Departments of Radiology and Bioengineering, Molecular Imaging Program at Stanford, Bio-X Program, Stanford University School of Medicine, Clark Centre, \\ 318 Campus Drive E150, Stanford, California, 94305, USA. Correspondence should be addressed to S.S.G. (sgambhir@stanford.edu.).
}

Published online 12 July 2007; doi:10.1038/nprot.2007.228

Positron emission tomography (PET) reporter probes (PRPs) are used to detect PET reporter gene (PRG) expression in living subjects. This article details protocols for analyzing the biodistribution of a PRP used to detect herpes simplex virus 1 thymidine kinase (HSV1-tk) or mutant HSV1-sr39tk PRG expression. However, the methods described are generalizable to other beta- or gamma/ positron-emitting probes. Accumulation of PRPs in animal tissues can be determined by counting PRP activity of isolated tissues, whereas digital whole-body autoradiography (DWBA) provides high-resolution images of PRP biodistribution in 5- to 45- $\mu \mathrm{m}$ tissue slices of killed research animals at a single time point. Biodistribution assay results may be obtained in less than a week after beginning the assay, and DWBA image acquisitions can take up to 3 months depending on the probe's radioisotope.

\section{INTRODUCTION}

Radiolabeled molecular probes have long been used to study various molecular events in biological systems. The invention of gamma cameras, single photon emission computerized tomography and PET allowed application of probes labeled with gamma- or positron-emitting radioisotopes for physiological or molecular imaging in living subjects, from small animals to humans. However, in preclinical studies, tissue biodistribution assays and DWBA still play an important role in determining specific tissue accumulation of radiolabeled probes at a single time point and with high sensitivity in research animals. Tissue biodistribution studies are useful for detection of low-level probes in the tissues of research animals, and the procedures do not require any expensive instrumentation. However, the disadvantages of this assay are that one can only determine the biodistribution of a probe in an animal at a single time point and it may take several days to obtain the results. DWBA has the same disadvantages, but it can provide highresolution tomographs of a probe's tissue accumulation at the time the research animal is killed for analysis.

In this protocol, we describe procedures for tissue biodistribution analysis and DWBA assay of a PRP in mice. Examples of common reporter probes used for the detection of HSV1-tk or mutant HSV1-sr39tk PRG expression include $\left[{ }^{3} \mathrm{H}\right] \mathrm{PCV}$, $\left[{ }^{14} \mathrm{C}\right]$ FIAU, $\left[{ }^{124} \mathrm{I}\right] \mathrm{FIAU}$ and $\left[{ }^{18} \mathrm{~F}\right] \mathrm{FHBG}{ }^{1-5}$. We have provided detailed backgrounds of these PRP/PRG systems in two previous Nature Protocols publications ${ }^{6-8}$. In addition to enabling high resolution and sensitivity detection of PRGs, tissue biodistribution analysis and DWBA allow the study of pharmacokinetics of any novel radiolabeled probe. These studies can also be used to confirm the results of animal SPECT or PET imaging9.

Reporter probe biodistribution studies are often performed using mouse models designed to express PRGs in specific parts of their body. For example, tumors may have been implanted in these mice that stably express these PRGs, or the PRGs may have been delivered to specific tissues with transgene delivery vectors. Otherwise, one may study the biodistribution of any beta- or gamma/positronradiolabeled probe in a normal mouse. This is often done to evaluate the pharmacokinetics of new probes before testing them for target specificity in animal studies. The amount of $\left[{ }^{3} \mathrm{H}\right] \mathrm{PCV}$ or $\left[{ }^{14} \mathrm{C}\right]$ FIAU injected is between 1 and $5 \mu \mathrm{Ci}\left(2.22-11.1 \times 10^{6} \mathrm{disin}-\right.$ tegrations per minute). The amount of $\left[{ }^{18} \mathrm{~F}\right] \mathrm{FHBG}$ can be $200 \mu \mathrm{Ci}$, which is usually used for PET imaging of mice. The amount of radioactivity affects the time period required for exposure of tissue to DWBA films. The time interval between injection of probe and killing of the mouse for biodistribution studies is at the discretion of the investigator. However, the half-life of ${ }^{18} \mathrm{~F}$ (109 $\mathrm{min}$ ) should be taken into consideration when planning this time interval.

\footnotetext{
MATERIALS

REAGENTS

- $\left[{ }^{3} \mathrm{H}\right]$ Penciclovir $\left(\left[{ }^{3} \mathrm{H}\right] \mathrm{PCV}\right)$, specific activity $=22 \mathrm{Ci} \mathrm{mmol}^{-1}$ (Moravek Biochemicals)

- 1-(2-Deoxy-2-fluoro- $\beta$-D-arabinofuranosyl)-5-iodouracil, [uracil-2- ${ }^{14} \mathrm{C}$ ] $\left(\left[{ }^{14} \mathrm{C}\right]\right.$ FIAU), specific activity $=55 \mathrm{mCi} \mathrm{mmol}^{-1}$ (Moravek Biochemicals) -9-(4- ${ }^{18}$ F-fluoro-3-[hydroxy-methyl]butyl)guanine ( $\left.\left[{ }^{18} \mathrm{~F}\right] \mathrm{FHBG}\right)$, specific

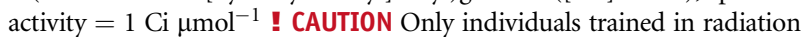
safety should handle radiochemicals. To reduce exposure to ionizing radiation from gamma rays, use lead shielding, limit exposure time to what is necessary and increase the distance from radiation sources as much as possible. $\cdot 0.1 \%(\mathrm{w} / \mathrm{v})$ SDS

-1.0 M benzethonium hydroxide (Hyamine) in methanol

- Cytoscint ES (MP Biomedicals, cat. no. 882475)

-9.7 M hydrogen peroxide (wrapped in an aluminum foil and stored in refrigerator)
}

\author{
-17.4 M glacial acetic acid \\ - Carboxymethyl cellulose, sodium salt \\ EQUIPMENT \\ - Liquid scintillation counter (LS 6500, Beckman Coulter). For information, \\ visit the following website: http://www.beckman.com/products/instrument/ \\ analytical/scintillation/ls6500_countingsystems_inst_dcr.asp \\ - Automatic gamma counters: Perkin Elmer (Packard) COBRA II or Wallac \\ Wizard \\ - Phosphoimager film (Perkin-Elmer) \\ - Phosphorimager film developer: Cyclone (Perkin-Elmer) \\ REAGENT SETUP \\ Preparation of $\left[{ }^{18} \mathrm{~F}\right]$ FHBG Currently, $\left[{ }^{18} \mathrm{~F}\right] \mathrm{FHBG}$ should be synthesized at a \\ radiochemistry facility within the vicinity of the small animal imaging facility \\ and the nuclear medicine clinic. Please refer to manuscripts written by Yaghoub \\ et al. ${ }^{5}$, Penuelas et al. ${ }^{10}$, Shiue et al. ${ }^{11}$, Alauddin et al. ${ }^{12}$ and Ponde et al. ${ }^{13}$ for
}


procedures to prepare $\left[{ }^{18} \mathrm{~F}\right] \mathrm{FHBG}$. If a cyclotron is not available at your institution, you may contact Dr. Sanjiv Gambhir at the Molecular Imaging Program at Stanford (sgambhir@stanford.edu).

Preparation of carboxymethyl cellulose This is prepared as follows: (i) Add 4 liters of water to a container that will hold at least 5 liters. Warm water may be used. (ii) While stirring the water, slowly add $150 \mathrm{~g}$ carboxymethyl cellulose (CMC) powder. (iii) Mix with gloved hands for $5 \mathrm{~min}$ to break up the powder. (iv) Leave the mixture overnight and then mix again for $5 \mathrm{~min}$. (v) Store the mixture at $4{ }^{\circ} \mathrm{C}$ in a refrigerator.

EQUIPMENT SETUP

CryoMacrotome Example 1: Leica CM3600. For information, visit the following website: http://www.leica-microsystems.com/website/
lms.nsf?opendatabase\&path=/WebSite/Products.nsf/(ALLIDs)/ 3198A113D19D66B0C1256A4F00485AC7. Example 2: Bright 5030/WD/MR (Hacker Instruments).

Scintillation counter calibration Scintillation counters only count a percentage of the total disintegrations from $\beta^{+}$emissions. Therefore, it is important to determine the efficiency factors of the scintillation counter for tritium. This can be determined by using a tritium standard vial (having a known amount of activity) and counting the vial and then calculating the percentage of the known activity equivalent to the actual count. The Beckman Coulter LS6500 in our laboratory has an efficiency factor of $59.2 \%$ for tritium and $78.7 \%$ for ${ }^{14} \mathrm{C}$. The counting efficiency of the gamma counter should also be determined.

\section{PROCEDURE}

\section{Analyzing the biodistribution of radiolabeled HSV1-tk/HSV1-sr39tk reporter probes in mice}

1) Administer the appropriate amount of the radiolabeled probe into the mouse. $\left[{ }^{3} \mathrm{H}\right] \mathrm{PCV},\left[{ }^{14} \mathrm{C}\right] \mathrm{FIAU}$ and $\left[{ }^{18} \mathrm{~F}\right] \mathrm{FHBG}$ are usually injected through a lateral tail vein. Between 1 and $5 \mu \mathrm{Ci}$ of $\left[{ }^{3} \mathrm{H}\right] \mathrm{PCV}$ and $\left[{ }^{14} \mathrm{C}\right] \mathrm{FIAU}$ and approximately $200 \mu \mathrm{Ci}$ of $\left[{ }^{18} \mathrm{~F}\right] \mathrm{FHBG}$ are usually injected. We recommend not to inject less than $0.5 \mu \mathrm{Ci}$ of $\left[{ }^{3} \mathrm{H}\right] \mathrm{PCV}$ and $\left[{ }^{14} \mathrm{C}\right] \mathrm{FIAU}$ or $50 \mu \mathrm{Ci}$ of $\left[{ }^{18} \mathrm{~F}\right] \mathrm{FHBG}$.

! CAUTION All animal experiments should be performed in accordance with relevant guidelines and regulations of protocols approved by your institution's animal research review committees. Also, you should be trained to work with radioisotopes before starting the following studies.

2| At the desired analysis time after probe administration, perform either (A) a tissue biodistribution assay or (B) a DWBA assay after killing the mouse using an approved method.

\section{(A) Biodistribution assay $\bigcirc$ TIMING Less than a week}

(i) Designate scintillation vials for the tissues of interest and weigh each of the empty vials. Usually the following organs are studied in a preliminary biodistribution assay: right kidney, left kidney, liver, brain, heart (one mouse heart dissolves completely), lung, skin (shaved), stomach (emptied), intestine (emptied), large bowel (emptied), bone, fat, blood, tail, muscle, spleen, bladder, thymus glands. However, you can harvest other tissues of interest, such as tumors or lymph nodes.

(ii) Harvest the tissues of interest and place between 50 and $150 \mathrm{mg}$ in the designated scintillation vials. Weigh the vials.

(iii) Add $1 \mathrm{ml}$ of Hyamine (1.0 M) and cap the vials tightly.

(iv) Place vials in a $65^{\circ} \mathrm{C}$ water bath. It may take several days (at least overnight) to digest most tissues.

(v) After all tissues have been digested, add $100 \mu \mathrm{l}$ of hydrogen peroxide (wrapped in an aluminum foil and stored in refrigerator) and $50 \mu \mathrm{L}$ glacial acetic acid. Recap vials and mix the contents by vigorous shaking. Place vials in the same water bath and check periodically to make sure the tissue has become colorless. Vortexing the vials from time to time can help tissues get digested and completely dissolved faster.

$\triangle$ CRITICAL STEP Scintillation counts may not be accurate if the contents of the vial are not colorless. It is important that the liquid in the vial becomes as clear as possible.

(vi) Add $10 \mathrm{ml}$ of Cytoscint fluid to each vial.

(vii) Cover the vials with aluminum foil to protect from light and leave it for $1 \mathrm{~h}$.

(viii) Count the activity of tritium or ${ }^{14} \mathrm{C}$ for 1 min with a scintillation counter.

(ix) Count the activity of ${ }^{18} \mathrm{~F}$ with a gamma counter.

(x) Convert counts per minute $(\mathrm{cpm})$ to disintegrations per minute by dividing the $\mathrm{cpm}$ with the counters efficiency factor. $1 \mathrm{Ci}=3.7 \times 10^{10}$ disintegrations per second. Divide the activity in the tissue by the injected dose and the gram of tissue, then multiply by 100 to obtain percentage of injected dose per gram.

\section{(B) DWBA TIMING Up to 3 months}

(i) Store the film cartridges in a freezer for later use.

(ii) Shave the excess fur and whiskers of the mouse.

(iii) Empty the bladder, either by squeezing it or by using a 28-gauge syringe to draw out as much urine as possible.

(iv) Position the mouse as desired on a styrofoam board and secure in place using U-shaped pins or staples around the arms and legs.

(v) Lay 1 inch of CMC on the metal chuck, where the animal will be set. Insert two 50-mL Falcon tube end caps into CMC until caps are on the chuck surface. Be sure the end caps are linear in the center of the chuck, parallel to the length of the chuck.

(vi) Take enough liquid nitrogen (approximately 3-4 inches deep) in a styrofoam container to submerge the specimen-styrofoam construct and submerge the construct for $15 \mathrm{~s}$.

(vii) Separate the specimen from the styrofoam board and dip it back into liquid nitrogen for an additional $10 \mathrm{~s}$. 
$\triangle$ CRITICAL STEP It is important to leave the specimen in liquid nitrogen long enough to ensure thorough freezing, yet not so long that the specimen starts to crack.

(viii) To remove the tail, use strong scissors or wire cutters to snip the tail one centimeter away from the body, while the specimen is still frozen.

(ix) Immediately place the specimen in CMC and push firmly until the subject is lying on the falcon end caps. Be sure the specimen is positioned so that the blade will slice from anterior to posterior. Add CMC to cover the entire specimen. Squeeze out any large air bubbles that might still be in the CMC.

(x) Place the entire chuck-CMC-specimen construct into the remaining liquid nitrogen and allow it to freeze for $10 \mathrm{~min}$. Add more liquid nitrogen if necessary.

(xi) Remove the construct from liquid nitrogen and store at $-20{ }^{\circ} \mathrm{C}$ for at least $1 \mathrm{~h}$. The specimen is now ready to be sliced. The attached movie illustrates the process of DWBA (Supplementary Video 1 online).

(xii) Animal sectioning. Oil all moving parts of the macrotome, including the metal rails, the elevator arms and the wells. ! CAUTION The Leica macrotome has a very sharp blade. Whenever you use the cryostat, you need to be alert and be careful not to have your arms or hands in front of the blade.

(xiii) Place the chuck into the macrotome and adjust it so that it is level. Secure the chuck tightly.

(xiv) Raise the blade to the highest level of the CMC.

(xv) Begin slicing at 100-200 $\mu \mathrm{m}$ thickness until the subject begins to become exposed. The slices must be thin enough to prevent chipping. When the subject becomes exposed, reduce the slice thickness to $45 \mu \mathrm{m}$. Periodically check the chuck to make sure it is still at level.

(xvi) When a desired slice is reached, place a ruler on the CMC next to the subject and photograph the entire region with a digital camera. Mark the first slice with the specimen name and date.

(xvii) Place a layer of label guard tape over the entire specimen and apply firm pressure on the entire surface. Leave 2-3 inches of exposed tape on the end closest to the blade.

(xviii) Hold the end of the tape closest to the blade, while using your knees to move the slicer and guide the tape off the blade. Do not pull on the tape since the slice may tear or fall off the tape.

(xix) Set the slice on a tray next to the blade.

! CAUTION Any extended duration of warmth will melt the slice and render it useless; thus, it is important to keep the slice inside the macrotome at all times.

(xx) Place as many slices that will fit into a cartridge and record the order. Cover a blanked digital film (a digital film that has been cleared of radiographs, using a light exposure device) with Saran wrap and place over the slices, facing the slices.

$\triangle$ CRITICAL STEP Make sure that you use a blanked digital film.

(xxi) Close the cartridge and store at $-20^{\circ} \mathrm{C}$.

(xxii) Film development. Allow the films to develop for the appropriate amount of time to yield good images and remove from the $-20{ }^{\circ} \mathrm{C}$ storage. For ${ }^{18} \mathrm{~F}$-conjugated probes, we usually expose the films to slices overnight, and for iodine-124 probes 7-9 h of exposure usually yields good images. Tritium and ${ }^{14} \mathrm{C}$ probes require very long exposure times (2-3 months and several weeks, respectively).

(xxiii) Turn off all sources of strong light.

(xxiv) Remove the plate from the cartridge and unwrap it.

(xxv) Wipe the films with a Kim wipe and let them warm up.

(xxvi) Insert the film into the digital film developer and acquire images. ? TROUBLESHOOTING

\section{? TROUBLESHOOTING}

To avoid the problem of underexposing the films, it would be good to have two or three test plates, which can be kept exposed in the freezer for a longer time period. This still works, because tissue sections are only a few micrometers apart. Also, be careful not to contaminate the plate with your fingers/gloves, which might have touched the radioactive samples.

\section{ANTICIPATED RESULTS}

Tissue biodistribution assays and DWBA are useful for analyzing the accumulation of probes in the tissues of research animals at a single time point only, but offer the advantage of higher sensitivity and in the case of DWBA higher resolution $(\sim 100 \mu \mathrm{m}$ with $45 \mu \mathrm{m}$ slices) tomographs than with microPET imaging. Biodistribution assays and microPET imaging allow quantification of activity in tissues as a percentage of injected dose. The degree of accumulation of reporter probes in tissues expressing the HSV1-tk/HSV1-sr39tk PRGs relative to background depends on the transport of these probes into cells, the extent of HSV1-tk/HSV1-sr39tk enzyme-catalyzed phosphorylation of the probe and the extent of probe phosphorylation by mammalian thymidine kinase enzymes. In addition, probe activity will be detected in the organs involved in clearance of the probe 
Figure $1 \mid\left[{ }^{18} \mathrm{~F}\right] \mathrm{FHBG}$ microPET and $\left[{ }^{14} \mathrm{C}\right] \mathrm{FIAU}$ DWBA images of mice that were tail vein injected with (a) AdCMV-lacZ, (b) Ad-CMV-HSV1-tk or (c) AdCMV-HSV1-sr39tk. Each viral vector $\left(5 \times 10^{8}\right.$ $\mathrm{PFU})$ was injected $72 \mathrm{~h}$ before tail-vein injection of $\left[{ }^{18} \mathrm{~F}\right] \mathrm{FHBG}$. $\left[{ }^{14} \mathrm{C}\right] \mathrm{FIAU}$ was injected $3 \mathrm{~h}$ after microPET scanning. (d) Comparison of $\left[{ }^{18} \mathrm{~F}\right] \mathrm{FHBG}$ and $\left[{ }^{14} \mathrm{C}\right]$ FIAU accumulation in mice that were tail vein injected with three different kinds of adenoviral vectors ( $n=5$ for each group). Percentage of injected dose per gram of tissue $\left(\% \mathrm{ID} \mathrm{g}^{-1}\right)$ was calculated with microPET for $\left[{ }^{18} \mathrm{~F}\right] \mathrm{FHBG}$ and biodistribution study for $\left[{ }^{14} \mathrm{C}\right] \mathrm{FIAU}$. $\left[{ }^{14} \mathrm{C}\right]$ FIAU was injected $3 \mathrm{~h}$ after microPET scanning. Mice were killed $3 \mathrm{~h}$ after $\left[{ }^{14} \mathrm{C}\right] \mathrm{FIAU}$ administration. $\left[{ }^{18} \mathrm{~F}\right] \mathrm{FHBG}$ versus $\left[{ }^{14} \mathrm{C}\right] \mathrm{FIAU}$ accumulation was statistically insignificant in hepatocytes expressing AdCMV-lacZ $(1.1 \pm 0.2$ versus $1.4 \pm 0.3, P=0.83)$ or $\operatorname{HSV} 1$-tk $(5.2 \pm 0.4$ versus $4.4 \pm 0.5, P=0.17)$. On the other hand, $\left[{ }^{18} \mathrm{~F}\right] \mathrm{FHBG}$ accumulation was significantly higher than $\left[{ }^{14} \mathrm{C}\right]$ FIAU accumulation in hepatocytes expressing HSV1-sr39tk $(9.9 \pm 0.9$ versus $2.6 \pm 0.6$, $P<0.001)$. Values are mean \pm standard error (reprinted Figure 6 of Min et al. Eur. J. Nucl. Med. Mol. Imaging, 30:1547-1560 (2003) with permission from Springer) ${ }^{3}$.

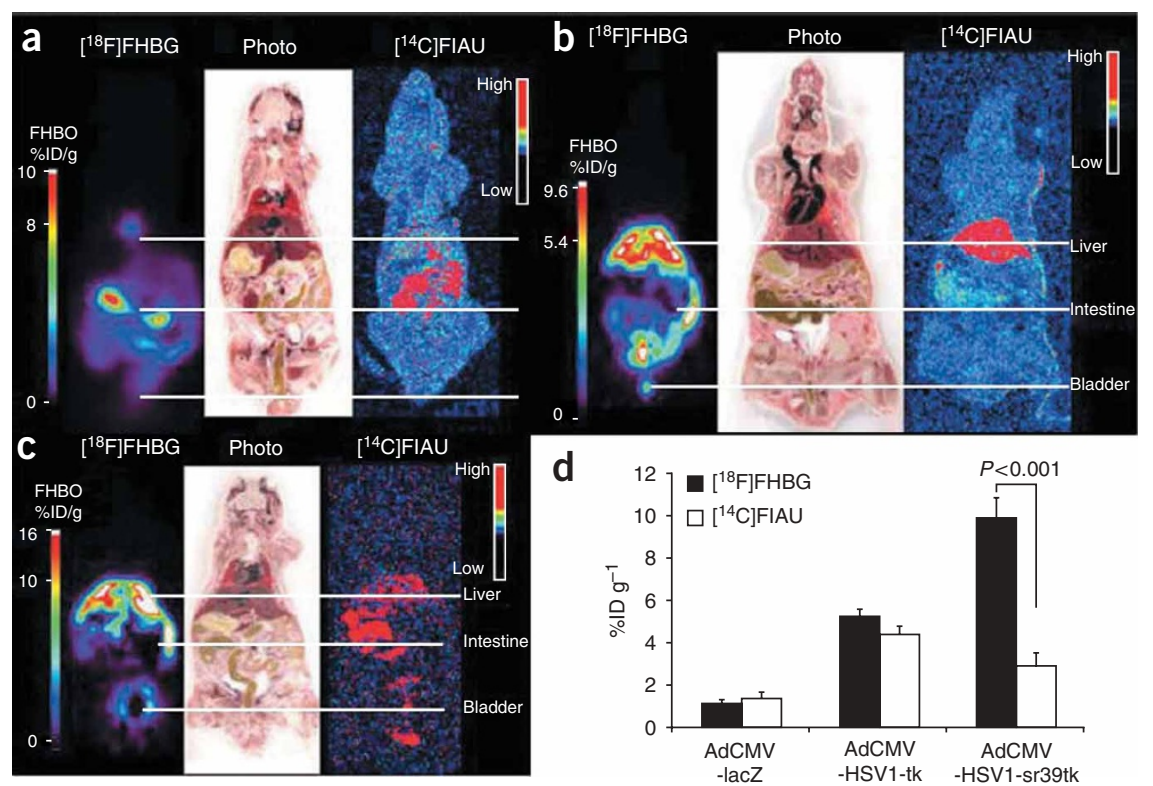

from the body, such as in the liver, kidneys, intestines and bladder. Figure 1a-c illustrates $\left[{ }^{18} \mathrm{~F}\right] \mathrm{FHBG}$ microPET images and $\left[{ }^{14} \mathrm{C}\right]$ FIAU DWBA of $(\mathbf{a})$ a control mouse, (b) a mouse expressing HSV1-tk PRG in its hepatocytes and (c) a mouse expressing the HSV1-sr39tk PRG in its hepatocytes ${ }^{3}$. $\left[{ }^{18} \mathrm{~F}\right] \mathrm{FHBG}$ and $\left[{ }^{14} \mathrm{C}\right] \mathrm{FIAU}$ accumulated to a similar extent in the HSV1-tk-expressing liver, but $\left[{ }^{18} \mathrm{~F}\right] \mathrm{FHBG}$ accumulation (as determined by microPET scan) was significantly higher than $\left[{ }^{14} \mathrm{C}\right] \mathrm{FIAU}$ accumulation (as determined by liver biodistribution assay) in the HSV1-sr39tk-expressing liver (Fig. 1d).

Note: Supplementary information is available via the HTML version of this article.

ACKNOWLEDGMENTS We acknowledge the contributions of Meera Iyer, Eileen Bauer, Khoi Nguyen, Gopal Sundaresan and Jung-Jun Min over the past decade in developing protocols for the detection of PET reporter genes in our laboratory. We also acknowledge grants from NIH, DOE and and RSNA Postdoctoral Fellowship in Basic Radiological Sciences.

COMPETING INTERESTS STATEMENT The authors declare no competing financial interests.

Published online at http://www.natureprotocols.com

Reprints and permissions information is available online at http://npg.nature.com/ reprintsandpermissions

1. Iyer, M. et al. 8- $\left[{ }^{18} \mathrm{~F}\right]$ Fluoropenciclovir: an improved reporter probe for imaging HSV1-tk reporter gene expression in vivo using PET. J. Nucl. Med. 42, 96-105 (2001).

2. Gambhir, S.S. et al. A mutant herpes simplex virus type 1 thymidine kinase reporter gene shows improved sensitivity for imaging reporter gene expression with positron emission tomography. Proc. Natl. Acad. Sci. USA 97, 2785-2790 (2000).

3. Min, J., Iyer, M. \& Gambhir, S.S. Comparison of $\left[{ }^{18} \mathrm{~F}\right] \mathrm{FHBG}$ and $\left[{ }^{14} \mathrm{C}\right] \mathrm{FIAU}$ for imaging of HSV1-tk reporter gene expression: adenoviral infection vs stable transfection. Eur. J. Nucl. Med. Mol. Imaging 30, 1547-1560 (2003).

4. Tjuvajev, J.G. et al. Imaging herpes virus thymidine kinase gene transfer and expression by positron emission tomography. Cancer Res. 58, 4333-4341 (1998).
5. Yaghoubi, S.S. et al. Human pharmacokinetic and dosimetry studies of $\left[{ }^{18} \mathrm{~F}\right] \mathrm{FHBG}$ : a reporter probe for imaging herpes simplex virus type- 1 thymidine kinase reporter gene expression. J. Nucl. Med. 42, 1225-1234 (2001).

6. Yaghoubi, S.S. \& Gambhir, S.S. Measuring herpes simplex virus thymidine kinase reporter gene expression in vitro. Nat. Protoc. 1, 2137-2142 (2006).

7. Yaghoubi, S.S. \& Gambhir, S.S. PET imaging of herpes simplex virus type 1 thymidine kinase (HSV1-tk) or mutant HSV1-sr39tk reporter gene expression in mice and humans using [ $\left.{ }^{18} \mathrm{~F}\right] \mathrm{FHBG}$. Nat. Protoc. 1, 3069-3075 (2007).

8. Kim, S.-J. et al. Seeing is believing: in vivo functional real-time imaging of transplanted islets using positron emission tomography (PET). Nat. Protoc. doi 10.1038/nprot.2006.491 (2007).

9. Bergstrom, M. et al. Autoradiography with positron emitting isotopes in positron emission tomography tracer discovery. Mol. Imaging Biol. 5, 390-396 (2003).

10. Penuelas, I. et al. A fully automated one pot synthesis of 9-(4- $\left[{ }^{18} \mathrm{~F}\right]$ fluoro-3hydroxymethylbutyl)guanine for gene therapy studies. Mol. Imaging Biol. 4, 415-424 (2003).

11. Shiue, G.G. et al. A simplified one-pot synthesis of 9-[(3- $\left[{ }^{18} \mathrm{~F}\right]$ fluoro-1-hydroxy-2propoxy)methyl] guanine $\left(\left[{ }^{18} \mathrm{~F}\right] \mathrm{FHPG}\right)$ and $9-\left(4-\left[{ }^{18} \mathrm{~F}\right]\right.$ fluoro-3hydroxymethylbutyl)guanine $\left(\left[{ }^{18} \mathrm{~F}\right] \mathrm{FHBG}\right)$ for gene therapy. Nucl. Med. Biol. 28, 875-883 (2001).

12. Alauddin, M.M. \& Conti, P.S. Synthesis and preliminary evaluation of 9- $\left(4-\left[{ }^{18} \mathrm{~F}\right]-\right.$ fluoro-3-hydroxymethylbutyl)guanine $\left(\left[{ }^{18} \mathrm{~F}\right] \mathrm{FHBG}\right)$ : a new potential imaging agent for viral infection and gene therapy using PET. Nucl. Med. Biol. 25, 175-180 (1998).

13. Ponde, D.E., Dence, C.S., Schuster, D.P. \& Welch, M.J. Rapid and reproducible radiosynthesis of $\left[{ }^{18} \mathrm{~F}\right] \mathrm{FHBG}$. Nucl. Med. Biol. 31, 133-138 (2004). 